DOI 10.37882/2223-2982.2020.12-2.21

\title{
МЕСТО ТОПОКОНЦЕПТА МАГАДАН В РУССКОЙ ЯЗЫКОВОЙ КАРТИНЕ МИРА
}

\section{TOPOCONCEPT MAGADAN LOCATION IN THE RUSSIAN LANGUAGE PICTURE OF THE WORLD ${ }^{2}$}

\section{Yu. Mageramova}

Summary: The article presents the results of the analysis of the structure of the toponymic concept of Magadan in the Russian linguistic picture of the world. The author proceeds from the position that the toponym, which is a concept, generalizes and reflects the collective historical and cultural experience in relation to a certain reality. In the course of the work, the methods of cognitive linguistics were used, which make it possible to make explicit the process of interaction between the language and its carrier during the conceptualization of space. By means of interpretive analysis of the obtained data, it was established that the conceptual core of the concept is the idea of the northern city - the capital of the "exiled Kolyma". The associative, connotative and axiological components of this concept are revealed.

Keywords: cognitive linguistics, concept, concept structure, toponyms, toponymic concept, topoconcept Magadan, linguistic picture of the world.

\section{Введение}

редставление об окружающем мире, по мнению современных ученых разных лингвоцентрических школ и направлений, сконцентрировано в сознании человека в виде особых ментальных структур - концептов. Вслед за В.И. Карасиком, мы признаем концепт «...ментальным образованием, имеющим множественные не сводимые друг к другу измерения, отражающим интерпретируемый мир и находящимся в системных динамических связях с однопорядковыми и разнопорядковыми знаковыми образованиями» [4, с. 93-94]. Сумма концептуальных знаний формирует языковую картину мира, в которой центральное положение занимают базовые мировоззренческие понятия: любовь, смерть, счастье, надежда, старость, вера, время и многие другие, которые зачастую не имеют существенных различий у разных народов. Этнические особенности восприятия действительности фиксируются в национальной языко-

\author{
Магерамова Юлия Юрьевна \\ К.филол.н., дочент, Северо-Восточный государственный \\ университет \\ mager.u@bk.ru
}

Аннотация: В статье представлены результаты анализа структуры топонимического концепта Магадан в русской языковой картине мира. Автор исходит из положения о том, что топоним, являющийся концептом, обобщает и отражает коллективный исторический и культурологический опыт в отношении определенной реалии. В ходе работы использованы методы когнитивной лингвистики, которые позволяют сделать явным процесс взаимодействия языка и его носителя в ходе концептуализации пространства. Путем интерпретационного анализа полученных данных установлено, что понятийным ядром концепта является представление о северном городе столице «ссыльной Колымы». Выявлены ассоциативные, коннотативные и аксиологические составляющие данного концепта.

Ключевые слова: когнитивная лингвистика, концепт, структура концепта, топонимы, топонимический концепт, топоконцепт Магадан, языковая картина мира.

вой картине мира, которая включает в себя важнейшие ментальные знания, рассмотренные сквозь призму национальной исторической и лингвокультурной специфики, накладывающей особый отпечаток на многие понятийные комплексы.

\section{Обзор литературы. Понятие о топонимическом коншепте в отечественном языкознании}

Безусловные достижения российской лингвоконцептологии XXI века состоят в детальном описании ряда важнейших концептов как в коллективном, так и в индивидуальном языковом сознании, в выявлении социолингвистических различий внутри общей языковой картины мира, в выработке методологических подходов к анализу и классификации концептов, в рассмотрении данных ментальных структур в синхроническом и диахроническом аспектах и др. Однако, как нам представляется, без должного внимания остаются такие

Работа выполнена при финансовой поддержке РФФИ, проект 20-012-00266 «Региональные варианты русского языка на Крайнем Северо-Востоке России»

2 This work was supported by the Russian Foundation for Basic Research, project 20-012-00266 «Regional variants of the Russian language in the Far North-East of Russia» 
немаловажные элементы концептосферы, как топонимы. Не вызывает сомнений, что не всякое наименование того или иного географического объекта способно стать значимым в масштабах национальной языковой картины мира: чаще всего, номинации подобного рода существенны на весьма ограниченной территории и для небольшого количества носителей языка. Топоним, являющийся концептом, обобщает и отражает коллективный исторический и культурологический опыт в отношении определенной реалии. По мнению О.А. Зобниной, топоним-концепт - это «ментальное образование, содержанием которого является знание о топонимической реалии, релевантной для определенного лингвокультурного сообщества» [3, с. 2]. Главными признаками топоконцептов, по мысли Е.А. Корнейко, является «...возможность ярко отражать культурно-ценностные представления об определенных географических объектах, общие для всего народа, способность вызывать мгновенные ассоциации при упоминании данных топонимических номинаций» [5, с. 7]. Лишь немногие наименования топообъектов в русской языковой картине мира обладают данными признаками: Москва, СанктПетербург, Байкал, Бородино, Волга, Крым, Сибирь, Чернобыль и некоторые другие топонимы можно с полным правом назвать концептуальными феноменами, обладающими сложной многомерной структурой, включающей понятийные, коннотативные, аксиологические и ассоциативные компоненты. Перспективой современных исследований является детальное описание важнейших топонимических концептов, существующих в русской языковой картине мира. По нашему убеждению, одним из таких общенациональных топонимов-концептов в XX веке стал город Магадан, который и сегодня являет собой знаковый феномен для любого носителя русского языка.

\section{Основные методы исследования топонимического коншепта Магадан}

Концептуальный подход к анализу топонимов обусловливает использование методов когнитивной лингвистики, которые позволяют сделать явными процесс взаимодействия языка и его носителя в ходе концептуализации пространства. Топонимическая система представляет в этом аспекте весьма показательный материал, В котором, по мнению В.Н. Телия, «концептуализированы не только знания о собственно человеческой, наивной картине мира и все типы отношений субъекта к ее фрагментам, но и как бы запрограммировано участие этих языковых сущностей вместе с их употреблением в межпоколенной трансляции эталонов и стереотипов национальной культуры» [10, с. 288]. Современная лингвоконцептология предлагает значительный арсенал методик, позволяющих вскрыть и описать структуру концепта. Так, исследователь О.Г. Орлова, подробно останавливаясь на базовых современных подходах к анализу концепта, на- зывает следующие основополагающие методологические принципы, лежащие в основе его современного лингвистического описания: антропоцентризм, принципиальная экспланаторность, экспансионизм, функционализм и текстоцентризм [9, с. 166]. Безусловно, все эти принципы лежат в основе частных методик исследования концептуальной сферы, которые разнятся преимущественно разными подходами к строению концепта и, как следствие, нетождественными приемами объективизации его структуры. Так, к примеру, представители Волгоградской школы лингвоконцептологических исследований выделяют три основных элемента, из которых выстраивается концепт: понятийный, образный и ценностный, а ученые Кемеровской школы предлагают шестикомпонентную структуру концепта, в которую входят следующие признаки: мотивирующий, образный, понятийный, оценочный, функциональный и символический [9, с. 167].

В нашем исследовании топонимического концепта Магадан была применена методика, предложенная Р.М. Фрумкиной [11, с. 55 - 67] и ставшая сегодня классической, согласно которой для определения и описания структуры того или иного концепта необходимо произвести следующие процедуры: путем обращения к лексикографическим источникам следует установить место концепта в языковом сознании носителей языка (в нашем случае было уместно лишь обращение к энциклопедическим словарям, так как имена собственные, как правило, не включены в словари толковые); выявить происхождение данного слова и роль его этимологии в формировании концепта; воспользоваться разнообразными контекстами использования топоконцепта (художественные, в том числе поэтические, публицистические и т.д.); включить в рассмотрение типичные ассоциации, которые возникают у носителей языка при упоминании анализируемого слова. Интерпретационный анализ полученных результатов позволяет, на наш взгляд, выявить понятийные, коннотативные, ценностные и ассоциативные компоненты в структуре рассматриваемого концепта.

\section{Результаты и обсужление. Топонимический коншепт Магадан и его составляюшие}

К группе топонимических концептов, несомненно, принадлежит и топоним Магадан - наименование города на Крайнем Северо-Востоке России, основанного в 1939 году и ставшего на долгое время символом несвободы, скорби, каторжного труда и сломанных человеческих судеб.

Название города с этимологической точки зрения неинформативно для носителя русского языка, так как имеет субстратное происхождение и лишено для русскоязычной языковой личности прозрачности внутренней формы. Большинство современных топонимистов 
сходятся во мнении о том, что этимоном послужило эвенское слово монгодан, которое переводится на русский язык как «морские наносы», «наносы моря», а также «плавник», «жилище из плавника». В топонимических словарях фигурируют и некоторые другие версии происхождения слова Магадан, которые представляются маловероятными и обязанными своим возникновением, скорее всего, явлению народной этимологии (Магадан жилище эвена Магды, Магадан - место сбора, восходящее к лексеме майдан и др.).

Анализ данных, представленных в электронной версии Большой российской энциклопедии [2], показал, что топоним Магадан обладает следующими ключевыми признаками, формирующими понятийное ядро данного концепта: город в России; административный чентр Магаданской области; население 98,9 тысяч человек; расположен в южной части области; расположен на реке Магаданка; расположен на берегу бухты Нагаева Охотского моря; крупнейший порт на Северо-Востоке России с круглогодичной навигацией; начальный пункт федеральной автотрассы «Колыма»; до 1953 года - административный чентр гостреста Дальстрой; при строительстве города использовался труд заключенных (в том числе японских военнопленных); за городом закрепилась слава столицы «ссыльной Колымы»; первые кирпичные застройки возводятся с 1933 года преимущественно в стиле советского неоклассицизма; основные отрасли машиностроение, химическая и пищевая (главным образом рыбная); в Магадане расположены офисы компаний по добыче драгоценных металлов и каменного угля. Данная экстралингвистическая информация содержит географические, исторические, экономические и культурные сведения о населенном пункте. Кроме того, одним из смысловых центров статьи энциклопедического словаря является упоминание о печальной «славе» города в качестве столицы «ссыльной Колымы». Именно этот признак лежит в основе формирования концептуального значения топонима Магадан, прочно закрепившегося в сознании носителей русского языка.

Этот вывод подтверждается и анализом основных ассоциаций, связанных со словом Магадан [1]. Имеющиеся в нашем распоряжении вербальные реакции на данное слово-стимул можно разделить на несколько групп: ассоциации, связанные с географическим (пространственным) положением города (Колыма, Россия, север, восток, Сибирь, Азия, далёко, дальний), ассоциации, указывающие на климатические и ландшафтные признаки Магадана (север, холод, снег, мороз, зима, холодно, море), ассоциации, связанные с административно-территориальным статусом этого населенного пункта (город, край, регион, страна, область). Кроме того, встретились единичные реакции типа человек, люди, дома, nорт, труднообъяснимая ассоциация поезд (как известно, этот вид наземного транспорта отсутствует на данной территории), фонетическая ассоциация маг, а также реакции песня, еду, ехать, которые предположительно могут быть вызваны связью с музыкальными произведениями, посвященными Магадану (в частности, с известной песней В. Высоцкого «Мой друг уехал в Магадан» или композицией исполнителя, выступающего под псевдонимом Вася Обломов, «Еду в Магадан»).

Однако одной из наиболее многочисленных стала группа ассоциаций, связанная с реализацией смыслового центра «несвобода, заключение, место ссылки»: тюрьма, ссылка, заключенные, посылочки, преступник, зек, зона. Опосредованно с этой группой, по нашему мнению, связаны также ассоциации Михаил, круг (Круг), которые отсылают к имени известного исполнителя песен в стиле шансон и автора довольно известной песни «Магадан». Именно эти ассоциации отражают историческую память народа о Магадане как городе, символизирующем пенитенциарную систему времен СССР.

Этот актуальный признак, известный носителям языка, входит в общенациональный концепт данного топонима и реализуется также во многих художественных текстах, посвященных Магадану. Особенно ярко данная коннотация проявляется в «Колымских рассказах» В. Шаламова, в романе-эпопее В. Гроссмана «Жизнь и судьба», в романе Е. Гинзбург «Крутой маршрут». Приведем в качестве иллюстрации несколько отрывков из этих произведений [8]: - Вас куда везут? - В Магадан. На расстрел. Мы приговорённые. [В.Т. Шаламов. Колымские рассказы (1954-1961)]. Когда ему докладывали об очередных вспышках «падежа» заключенных, он отвечал: «Новых получим. Поеду в Магадан. Добьемся». Он считал, что куда эфрективнее поехать в Магадан и добиться там свежих этапов, чем возиться с полумертвецами из политических эшелонов тридиать седьмого года... [Е.С. Гинзбург. Крутой маршрут: Часть 2 (1975-1977)]. В песне говорилось о холодных пароходных трюмах, о том, как ревел океан, и что «от качки страдали зека, обнявшись, как кровные братья», и как из тумана вставал Магадан - «столица Колымского края» [Василий Гроссман. Жизнь и судьба, часть 3 (1960)]. Следует отметить, что с течением времени и изменением политической ситуации в стране «лагерная» тематика уступает место новым мотивам художественных текстов: происходит своего рода романтизация севера, труда людей, осваивавших этот суровый край. Таким, например, предстает Магадан (названный в тексте просто Городом) в романе О. Куваева «Территория»: «Чинков не спеша прошел вверх, где Город взбегал на гору, а затем обрывался к самому морю. Город выглядел очень современным, культурным, потому что он был махом воздвигнут в эпоху архитектурных излишеств. Единый стиль башенок, колонн и выступов придавал ему законченный вид» [6]. На правах самостоятельного персонажа выступает Магадан в прозе А. Бирюкова [7, с. 136] на страницах его произведений (повестей «Не- 
известный вам Антон», «Три негодяя в одном сюжете», «Советы уезжающим на материк», романе «Свобода в широких пределах, или Современная амазонка») создается обаятельный образ современного города.

Романтизированный Магадан можно наблюдать и во многих песнях, посвященных этому городу: в известных произведениях В. Высоцкого «Мой друг уехал в Магадан» и «Я расскажу тебе про Магадан» развенчивается годами устоявшееся представление о Магадане как о лагерной столице (... ведь там сплошные лагеря, а в них - убийцы; не верь молве: их там не больше, чем в Москве), а отъезд лирических героев в этот северный город рассматривается как бегство от рутины, от цивилизации, решительный шаг, который становится поворотным пунктом в судьбе. Тема поездки в Магадан (вынужденной или сознательной) возникает и в других композициях об этом городе (Михаила Назарова «Сон», Михаила Круга «Магадан», Васи Обломова «Еду в Магадан» и др.). В большинстве этих музыкальных произведений можно наблюдать два основных мотива: во-первых, определенную идеализацию города и его суровой природы (город солнца Магадан; заснеженный рай; волшебный сон; сопки угрюмо спят; моря свинцовый цвет), во-вторых, воспоминание о лагерном прошлом, тюремная тема (на берегу стоят баржи колымских лет; ....на руке возник с чайками Магадан; мне приснилось ..., что кончился мой срок). Рассмотренные контексты позволяют расширить концептуальное наполнение топонима Магадан за счет включения в его базовую национально-культурную составляющую значения далекого сурового края, ме́ста для сильных людей, для преодоления себя и, как это ни странно, города свободы: свободы от груза повседневности, цивилизации, условностей.

Выделенные нами концептуальные признаки топонима Магадан находят свое отражение и в современных интернет-мемах, самым распространенным персонажем которых является И.В. Сталин как фигура, символизирующая политические репрессии. Зачастую мемы на магаданскую тему представляют собой визуально-сло- весные объекты (изображение Сталина с надписью, приобретающей зловещий смысл): «Тебе пора отдохнуть в солнечном Магадане», «Две девушки - две путевки в Магадан», «Вот ты уже в Магадане. И куда мне теперь тебя ссылать?», «Какой веселый - поедешь в Магадан», «Даю вам три варианта на выбор: расстрел, тюрьма, прописка в Магадане» и т.п. Кстати сказать, в одном из вышеназванных мемов реализуется устойчивое выражение солнечный Магадан. Не возникает сомнений в том, что эпитет солнечный по отношению к городу использован в ироническом, а скорее даже в саркастическом ключе: впервые данное словосочетание было произнесено капитаном Жегловым в известном фильме С. Говорухина «Место встречи изменить нельзя».

Неоднозначный эффект создают не так давно опубликованные магаданской художницей Н. Ковалевой графические работы со слоганом «Магадан - город, где тебя ждут» (с вариациями «Магадан - город, где у каждого есть летняя шапка», «Магадан - город, где живет зима»), центральными персонажами которых стали медведи. С одной стороны, эти изображения полны иронии, с другой - напоминают о реальной возможности столкнуться с этими хищниками в окрестностях города.

\section{ЗакАючение}

Интерпретационный анализ вышеизложенных фактов позволяет представить структуру топонимического концепта Магадан в следующем виде: понятийным ядром концепта в русской языковой картине мира является представление о северном городе - столице «ссыльной Колымы». Именно этот смысловой компонент обусловлен историко-культурными фактами и является актуальным для большинства носителей русского языка. Однако в многомерном строении данного концепта отмечаются и другие признаки, которые относятся к коннотативным: далекий, суровый, холодный, аскетичный, при этом обладающий своеобразным притяжением. Ценностная составляющая рассмотренного концептуального феномена фиксирует преимущественно негативное отношение носителей русского языка к данной реалии.

\section{ЛИТЕРАТУРА}

1. Ассоциации к слову Магадан [Электронный ресурс] // URL: https://kartaslov.ru/ассоциации-к-слову/Магадан (дата обращения 30.04.2020).

2. Гоголева Т.Ю., Павлинов П.С. Магадан [Электронный ресурс] // Большая российская энциклопедия - электронная версия. URL: https://bigenc.ru/ geography/text/2151561 (дата обращения 04.05.2020).

3. Зобнина 0.А. Концепт «0xbridge» В английской лингвокультуре: дис. ... канд. филол. наук / Волгоградский государственный педагогический университет. Волгоград, 2007. С. 2.

4. Карасик В.И. Языковая матрица культуры. М.: Гнозис, 2013. С. 93-94.

5. Корнейко Е.А. Белгородские топоконцепты и топонимические перифразы в составе региолекта Белгородской области // Научные ведомости. Серия Гуманитарные науки. 2013. № 6 (149). Выпуск 17. С.7.

6. Куваев 0. Территория [Электронный ресурc] // URL: https://knijky.ru/books/territoriya?page=6 (дата обращения 05.05.2020).

7. Магерамова Ю.Ю., Курочкина М.В. Городской пейзаж в творчестве А.М. Бирюкова // Колымский гуманитарный альманах. 2011. № 6. С. 136. 
8. Национальный корпус русского языка [Электронный ресурс] // URL: http://processing.ruscorpora.ru/search.xml?env=alpha\&mycorp=\&mysent=\&mysize $=\&$ mysentsize $=\& \mathrm{dpp}=\& \mathrm{spp}=\& \mathrm{spd}=\&$ mydocsize $=\&$ mode=main\&sort=i_grtagging\&lang=ru\&nodia=1\&text=lexform\&req=Магадан (дата обращения 04.05.2020).

9. Орлова 0.Г. Методология и методики современной лингвоконцептологии // Вестник Удмуртского университета. 2013. Вып. 2. История и филология. C. $166-172$.

10. Телия В.Н. Русская фразеология: семантический, прагматический и лингвокультурологический аспекты [Текст] / В.Н. Телия. - М.: Языки русской культуры, 1996. - С. 288.

11. Фрумкина Р.М. «Теории среднего уровня» В современной лингвистике // Вопросы языкознания. 1996. № 2. С. 55-67. Ассоциации к слову Магадан [Электронный ресурс] // URL: https://kartaslov.ru/ассоциации-к-слову/Магадан (дата обращения 30.04.2020).

12. Гоголева Т.Ю., Павлинов П.С. Магадан [Электронный ресурс] // Большая российская энциклопедия - электронная версия. URL: https://bigenc.ru/ geography/text/2151561 (дата обращения 04.05.2020).

13. Зобнина 0.А. Концепт «0xbridge» в английской лингвокультуре: дис. ... канд. филол. наук / Волгоградский государственный педагогический университет. Волгоград, 2007. С. 2.

14. Карасик В.И. Языковая матрица культуры. М.: Гнозис, 2013. С. 93-94.

15. Корнейко Е.А. Белгородские топоконцепты и топонимические перифразы в составе региолекта Белгородской области // Научные ведомости. Серия Гуманитарные науки. 2013. № 6 (149). Выпуск 17. С.7.

16. Куваев 0. Территория [Электронный ресурc] // URL: https://knijky.ru/books/territoriya?page=6 (дата обращения 05.05.2020).

17. Магерамова Ю.Ю., Курочкина М.В. Городской пейзаж в творчестве А.М. Бирюкова // Колымский гуманитарный альманах. 2011. № 6. С. 136.

18. Национальный корпус русского языка [Электронный ресурс] // URL: http://processing.ruscorpora.ru/search.xml?env=alpha\&mycorp=\&mysent=\&mysize $=\&$ mysentsize $=\& d p p=\& s p p=\& s p d=\&$ mydocsize=\&mode=main\&sort=i_grtagging\&lang=ru\&nodia=1\&text=lexform\&req=Магадан (дата обращения 04.05.2020).

19. Орлова 0.Г. Методология и методики современной лингвоконцептологии // Вестник Удмуртского университета. 2013. Вып. 2. История и филология. C. $166-172$.

20. Телия В.Н. Русская фразеология: семантический, прагматический и лингвокультурологический аспекты [Текст] / В.Н. Телия. - М.: Языки русской культуры, 1996. - С. 288.

21. Фрумкина Р.М. «Теории среднего уровня» в современной лингвистике // Вопросы языкознания. 1996. № 2. С. 55-67.

( Магерамова Юлия Юрьевна (mager.u@bk.ru).

Журнал «Современная наука: актуальные проблемы теории и практики»

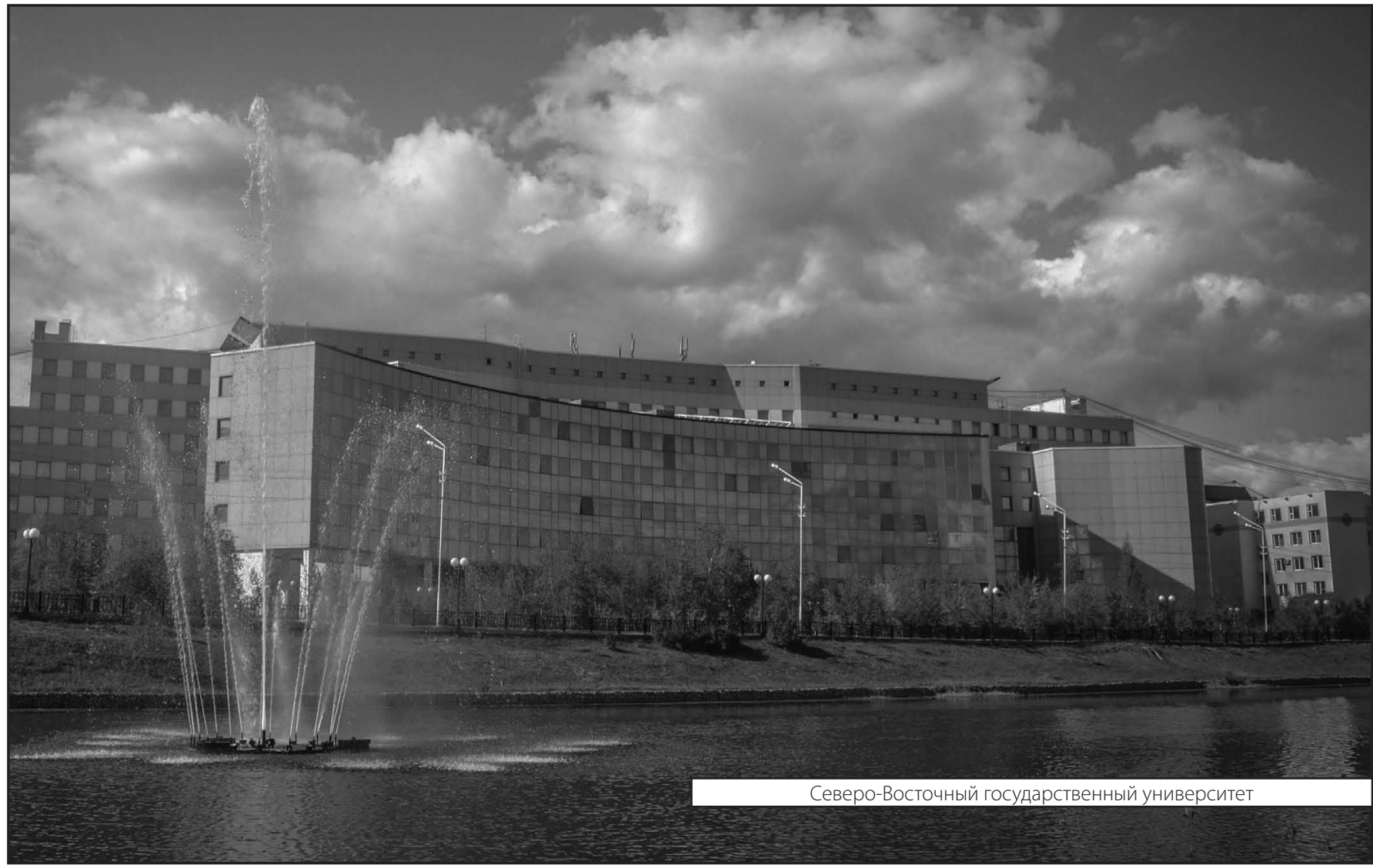

